Psychological Medicine, 1979, 9, 605-609

Printed in Great Britain

\title{
EDITORIAL
}

\section{Anxiety and the brain: not by neurochemistry alone ${ }^{1}$}

There has recently been a great flurry of excitement over the discovery of receptors in the central nervous system that specifically bind benzodiazepines (Squires \& Braestrup, 1977; Möhler \& Okada, 1977). This might be the long-awaited clue that will direct us to the brain systems on which the anti-anxiety drugs act, and which therefore presumably mediate anxiety. Clue it certainly is; but one which will need cautious interpretation alongside the evidence gathered by other means of studying the neuropsychology of anxiety. Taken in isolation it could yet turn out to be a sign-post which points clearly, but in the wrong direction; indeed, there are already indications that this may be so.

Benzodiazepine receptors have been found all over the brain, with a particularly heavy concentration in the neocortex (Braestrup \& Squires, 1977; Williamson et al. 1978). I shall argue later that, if one is to do justice to the complexities of anxiety, it is essential to recognize that it has cognitive as well as emotional aspects. Even so, the neocortex does not look right as the primary site of action of an anti-anxiety drug. Experiments with animals suggest that the limbic system would be a better candidate for the seat of emotional experience and the mediator of emotional behaviour. While there is a reasonably dense concentration of benzodiazepine receptors in various parts of the limbic system, there is also a high concentration in the cerebellum (Braestrup \& Squires, 1977; Williams et al. 1978); yet the latter structure is mainly concerned with motor behaviour. Worse still, there is quite a high concentration of benzodiazepine receptors in the spinal cord (Möhler \& Okada, 1977; Robertson et al. 1978); and while this might have comforted an earlier generation of animal psychologists (e.g. Mowrer, 1947), who sought a purely peripheral account of fear, it is unlikely to find favour today as a site for anxiety in human beings.

The ubiquity of benzodiazepine receptors in the nervous system is perhaps linked to their association with $\gamma$-amino butyric acid (GABA), the equally wide-spread inhibitory neurotransmitter. There has been evidence for some time that the benzodiazepines facilitate the action of GABA-ergic systems (Costa \& Greengard, 1975; Macdonald \& Barker, 1978). The elegant biochemical experiments of Costa's group at NIMH (Guidotti et al. 1978) now suggest that benzodiazepine receptors are closely associated with (but not identical to) GABA receptors. This group has proposed that the endogenous ligand which normally occupies the benzodiazepine receptor is an inhibitor of GABA's binding to its own receptor (Guidotti et al. 1978). The action of the benzodiazepines in vivo is then seen to consist in the displacement of this endogenous inhibitor of GABA binding, with a consequent facilitation of GABA-ergic activity. The logic of this argument turns GABA itself into a kind of endogenous anti-anxiety agent. There is some support for this view in the recent experiments of Soubrié et al. (1978), who have found that picrotoxin, which can block the inhibitory action of GABA, alters the behaviour of the rat in a number of ways which are consistent with an increase in anxiety. But the key prediction that follows from the argument-namely, that drugs which promote the activity of GABA should possess anti-anxiety action - has so far not been confirmed, in spite of efforts to demonstrate such an action using amino-oxyacetic acid, which increases the level of GABA in the brain (Cook \& Sepinwall, 1975). There is, as yet, no good explanation for these inconsistent findings with picrotoxin and amino-oxyacetic acid; however, the exact neurochemical effects produced by both these drugs are still obscure.

The solution to these problems might lie in the realization that the benzodiazepines are more than simply anti-anxiety drugs: they are also, among other things, centrally acting muscle-relaxants and anti-convulsants (Randall \& Kappell, 1973; Schallek et al. 1972; Browne \& Perry, 1973). The benzodiazepine receptors in the spinal cord might be related to either or both of these effects. As to

${ }^{1}$ Address for correspondence: Dr J. A. Gray, Department of Experimental Psychology, South Parks Road, Oxford OX1 3UD. 0033-2917/79/2828-4380 \$01.00 (C) 1979 Cambridge University Press 
the receptors in the brain, there is at least as good a case for linking them to the anti-convulsant properties of the benzodiazepines as to their anti-anxiety action. There is a considerable amount of evidence which suggests a relation between lowered GABA-ergic activity and convulsions (Meldrum, 1975); thus facilitation of GABA-ergic function is exactly what one would expect of an anti-convulsant drug. Furthermore, a recent report provides direct evidence of a relationship between benzodiazepine receptors and seizures: the experimental induction of seizures by electro-convulsive shock or by pentylenetetrazol was followed by a substantial and rapid increase in benzodiazepine binding in the brain (Paul \& Skolnick, 1978).

It is important to keep these other relationships of the benzodiazepines and their receptors in mind when interpreting evidence which, on the face of it, fits well with the anti-anxiety activity of these drugs. For example, our group in Oxford has recently collaborated with Professor P. B. Bradley's group in Birmingham in an investigation of benzodiazepine binding in the brains of rats from the Maudsley reactive and nonreactive strains, which have been selectively bred for, respectively, high and low fearfulness (Broadhurst, 1975). It was found that the Nonreactives had a higher density of benzodiazepine receptors throughout the brain (and the spinal cord) than the Reactives (Robertson et al. 1978), a finding which it is tempting to relate to the strain difference in fearfulness. However, the Nonreactive rats are also more susceptible to seizures than the Reactives (Gray, 1964), and this is an equally plausible behavioural correlate of the strain difference in benzodiazepine binding.

It might be thought that the fact that the benzodiazepines have other behavioural effects besides their ability to reduce anxiety renders nugatory the strategy of deducing the brain systems that mediate anxiety from an investigation of the brain systems on which the benzodiazepines act. But there are ways round this problem.

First, the benzodiazepines are not the only anti-anxiety drugs. Alcohol has always been ingested in large quantities for this purpose, and the barbiturates and meprobamate were extensively prescribed for it before the benzodiazepines swept them from favour. A review of the behavioural effects in animals of the barbiturates, alcohol and the benzodiazepines shows that, with minor exceptions, these three classes of drug affect behaviour in tasks relevant to anxiety (a phrase which is explained below) in an almost identical manner (Gray, 1977). The benzodiazepine receptor does not bind these other anti-anxiety drugs (Squires \& Braestrup, 1977; Möhler \& Okada, 1977); had it done so, it would have been a more plausible sign-post to the brain systems which mediate anxiety. Since it does not, there must be a final common pathway for the anti-anxiety drugs which lies beyond the benzodiazepine receptor. We can use the existence of different classes of anti-anxiety drug as a means to triangulate this final common pathway: it is where the actions of these classes of drug intersect that we should seek the brain systems which mediate anxiety.

Secondly, the benzodiazepines and other anti-anxiety drugs produce behavioural changes in animals which have been well described, of which we have a good theoretical understanding (derived from learning theory: Gray, 1975), and which are plausible as the changes one would expect to be produced by anti-anxiety agents (Gray, 1977, 1978). An economical and reasonably accurate description of these changes is that the anti-anxiety drugs block the behavioural effects of stimuli which warn of impending punishment, of stimuli which warn of frustrative non-reward (as defined by Amsel, 1962), and of novel stimuli (Gray, 1977). From this, one might deduce that anxiety consists in the state which is elicited by these three classes of stimuli (Gray, 1978). This definition of anxiety is based entirely on animal experiments. Yet it does not do badly as a description of clinical anxiety in man, especially with a little re-phrasing: anxiety is a state elicited by the threat of pain, loss or failure and by unfamiliar circumstances. Furthermore, the behavioural effects produced in experimental animals by these three classes of 'adequate stimuli for anxiety' (as one might boldly call them) are also plausible as analogues of the behavioural signs of human anxiety. They consist in the inhibition of ongoing behaviour (especially rewarded behaviour), an increased level of arousal, and increased attention to environmental cues, especially novel ones (Gray, 1975, 1977, 1978).

The existence in animals of these theoretical and experimental parallels to human anxiety gives 
one an invaluable double-check on the validity of any proposed identification of a particular brain structure as part of a system mediating anxiety. For it follows that intervention in the normal functioning of this structure should produce predictable effects on behaviour. If the intervention is such as to impair its normal functioning (e.g. a lesion), we should observe a reduction in anxiety (i.e. a reduction in the behavioural effects of the adequate stimuli for anxiety), as when we administer an anti-anxiety drug. Conversely, if the intervention is such as to increase its normal functioning (e.g. electrical stimulation), we should observe an increase in anxiety. Notice that one is not always in such a fortunate position in attempting to deduce relevant brain structures from drug action. For example, one of the greatest handicaps faced by workers interested in the neural basis of schizophrenia is that, while much is known about the neurochemical effects of anti-psychotic drugs, there is no behaviour in experimental animals to which these effects can be related and which is at the same time a plausible analogue of psychotic behaviour in man.

Arguments and experiments along these lines have been used to identify the septo-hippocampal system and its noradrenergic and serotonergic afferents as candidates for structures which mediate anxiety (Gray, 1970, 1978; Gray et al. 1978; Stein et al. 1973). This is not the place to repeat the evidence which supports these inferences. Rather, I should like briefly to relate this hypothesis to certain other views of the functions of the same structures.

The first of these alternative views has been expressed by Crow (1973) in this country and Stein (1968) in the United States. It is that the dorsal ascending noradrenergic bundle, which originates in the locus coeruleus in the brain stem and innervates much of the forebrain, including the septal area and the hippocampus (Ungerstedt, 1971), is the neural substrate of reward (Stein) or reinforcement (Crow). This suggestion is, of course, diametrically opposed to the hypothesis (Gray et al. 1975) that the dorsal noradrenergic bundle mediates responses to stimuli which warn of frustrative non-reward (a component of anxiety, as defined above). The reward hypothesis of the function of the dorsal noradrenergic bundle is largely based on the results of experiments on electrical selfstimulation of the brain (Rolls, 1975). Like the non-reward hypothesis, it too has been said by some of its proponents to have significance for psychiatry, though now it is schizophrenia (Stein \& Wise, 1972) rather than anxiety which occupies the centre of the stage. But recent experiments which have examined responses to natural reward (e.g. food), as distinct from electrical stimulation of the brain, in animals with virtually total destruction of the dorsal noradrenergic bundle have clearly disproved the reward hypothesis, while offering good support for the non-reward hypothesis. These animals learn and perform the rewarded response without difficulty, but show retarded extinction (Mason \& Iversen, 1975) and loss of the normal 'partial reinforcement effects' produced when nonrewarded trials are randomly intermixed with rewarded trials (Owen et al. 1979).

The second alternative view which I wish to consider is harder to summarize succinctly. It is not a single hypothesis, but rather a distillation of a variety of different views of the functions of the septo-hippocampal system, as expressed at a recent CIBA symposium on this topic (Elliott \& Whelan, 1978). These views differed in detail from one another in very many ways. But they all had in common the assumption that the septo-hippocampal system is concerned with cognitive rather than emotional functions. This might seem to imply that the hypothesis proposed here, that the septo-hippocampal system mediates anxiety, is excessively idiosyncratic. But this inference would be based on a false dichotomy between thought and emotion. Anxiety is as distinctive a state cognitively as it is emotionally: it shows itself as clearly in obsessional ruminations as in poundings of the heart, in indecision as much as in sweating of the palms.

After much discussion, the participants at the CIBA symposium were able to find common ground in their differing proposals as to the functions of the septo-hippocampal system. This lay in the proposal that this system functions as a match-mismatch comparator (A. H. Black, in Elliott \& Whelan, 1978, p. 418). This proposal is congenial to the theory of anxiety outlined here. For this theory may be stated as follows: the septo-hippocampal system has the task of monitoring ongoing activities, comparing achieved with desired goals, registering discrepancies (punishment, non-reward, failure) and threats of discrepancies, bringing ongoing activities to a halt when such registrations occur, and searching for better alternative courses of action. On this analysis, the clinical 
symptom which is most characteristic of anxiety is obsessional checking, not the simple phobia (which has more traditionally fallen easy prey to accounts based on learning theory). In sum, as the Soviet physiologist, Simonov, put it, the septo-hippocampal system is 'an organ of hesitation and doubt'. We all need such an organ; it is when it becomes pathologically over-active (usually in predisposed individuals: Eysenck, 1967; Gray, 1973) that one sees the clinical phenomena of anxiety.

An important question remains: what synaptic and neural events intervene between the binding of the benzodiazepines to their receptor and the action which (ex hypothesi) they exert on the septohippocampal system? To this question there is, as yet, no answer. The ubiquity of benzodiazepine binding in the brain makes it difficult to see how a precisely localized site of action can be attributed to these drugs. The ubiquity of GABA poses an analogous problem. But the demonstration of increased anxiety after picrotoxin administration (Soubrié et al. 1978), and the evidence that the barbiturates (like the benzodiazepines) facilitate the action of GABA (Ransom \& Barker, 1976; Barker \& Ransom, 1978), both reinforce the likelihood that this neurotransmitter is intimately concerned with the regulation of anxiety. Fuxe et al. (1975) have suggested that GABA-ergic afferents to the locus coeruleus play a critical role in this regulation. Alternative possibilities lie in the GABA-ergic terminals in the lateral septal area (McLennan \& Miller, 1974, 1976) or in the hippocampus (Storm-Mathisen, 1978). Resolution of this problem will provide a lively challenge to research in the next few years.

J. A. GRAY

My thanks are due to Drs Jane Mellanby and Ian Martin for helpful comments on the manuscript.

\section{REFERENCES}

Amsel, A. (1962). Frustrative nonreward in partial reinforcement and discrimination learning: some recent history and a theoretical extension. Psychological Review 69, 306328.

Barker, J. L. \& Ransom, B. R. (1978). Pentobarbitone pharmacology of mammalian central neurones grown in tissue culture. Journal of Physiology 280, 355-372.

Braestrup, G. \& Squires, R. F. (1977). Specific benzodiazepine receptors in rat brain characterized by highaffinity $\left[{ }^{3} \mathrm{H}\right]$-diazepam binding. Proceedings of the National Academy of Sciences, USA 74, 3805-3809.

Broadhurst, P. L. (1975). The Maudsley reactive and nonreactive strains of rats: a survey. Behavior Genetics 5,299 319.

Browne, T. R. \& Perry, J. K. (1973). Benzodiazepines in the treatment of epilepsy, Epilepsia 14, 277-310.

Cook, L. \& Sepinwall, J. (1975). Behavioral analysis of the effects and mechanisms of action of benzodiazepines. In Mechanism of Action of Benzodiazepines (ed. E. Costa and P. Greengard), pp. 1-28. Raven Press: New York.

Costa, E. \& Greengard, P. (eds.) (1975). Mechanism of Action of Benzodiazepines. Raven Press: New York.

Crow, T. J. (1973). Catecholamine-containing neurones and electrical self-stimulation. 2. A theoretical interpretation and some psychiatric implications. Psychological Medicine $3,66-73$.

Elliott, K. \& Whelan, J. (eds.) (1978). Functions of the SeptoHippocampal System. CIBA Foundation Symposium no. 58 (new series). Elsevier: Amsterdam.

Eysenck, H. J. (1967). The Biological Basis of Personality. C. C. Thomas: Springfield, Ill.

Fuxe, K., Agnati, L. F., Bolme, P., Hökfelt, T., Lidbrink, P., Ljungdahl, A., Perez de la Mora, M. \& Ógren, S.-O. (1975). The possible involvement of GABA mechanisms in the action of benzodiazepines on central catecholamine neurons. In Mechanism of Action of Benzodiazepines (ed. E. Costa and P. Greengard), pp. 45-61. Raven Press: New York.

Gray, J. A. (1964). The relation between stimulus intensity and response strength in the context of Pavlovian personality theory. Unpublished Ph.D. thesis: University of London.
Gray, J. A. (1970). Sodium amobarbital, the hippocampal theta rhythm and the partial reinforcement extinction effect. Psychological Review 77, 465-480.

Gray, J. A. (1973). Causal theories of personality and how to test them. In Multivariate Analysis and Psychological Theory (ed. J. R. Royce), pp. 409-463. Academic Press: London.

Gray, J. A. (1975). Elements of a Two-Process Theory of Learning. Academic Press: London.

Gray, J. A. (1977). Drug effects on fear and frustration: possible limbic site of action of minor tranquillizers. In Handbook of Psychopharmacology (ed. L. L. Iversen, S. D. Iversen and S. H. Snyder), pp. 433-529. Plenum: New York.

Gray, J. A. (1978). The 1977 Myers Lecture: The neuropsychology of anxiety. British Journal of Psychology 69, $417-434$.

Gray, J. A., McNaughton, N., James, D. T. D. \& Kelly, P. H. (i 975). Effect of minor tranquillisers on hippocampal theta rhythm mimicked by depletion of forebrain noradrenaline. Nature 258, 424-425.

Gray, J. A., Feldon, J., Rawlins, J. N. P., Owen, S. \& McNaughton, N. (1978). The role of the septo-hippocampal system and its noradrenergic afferents in behavioural responses to nonreward. In Functions of the Septo-Hippocampal System (ed. K. Elliott and J. Whelan), pp. 275-300. CIBA Foundation Symposium no. 58 (new series). Elsevier: Amsterdam.

Guidotti, A., Toffano, G. \& Costa, E. (1978). An endogenous protein modulates the affinity of GABA and benzodiazepine receptors in rat brain. Nature $275,553-555$.

Macdonald, R. L. \& Barker, J. L. (1978). Benzodiazepines specifically modulate GABA-mediated postsynaptic inhibition in cultured mammalian neurones. Nature 271, 563-564.

Mason, S. T. \& Iversen, S. D. (1975). Learning in the absence of forebrain noradrenaline. Nature 258, 422-424.

McLennan, H. \& Miller, J. J. (1974). The hippocampal control of neuronal discharges in the septum of the rat. Journal of Physiology 237, 607-624.

McLennan, H. \& Miller, J. J. (1976). Frequency-related inhibitory mechanisms controlling rhythmical activity in the septal area. Journal of Physiology 254, 827-841. 
Meldrum, B. S. (1975). Epilepsy and $\gamma$-aminobutyric acidmediated inhibition. International Review of Neurobiology 17, 1-36

Möhler, H. \& Okada, T. (1977). Benzodiazeipne receptor: demonstration in the central nervous system. Science 198 849-851.

Mowrer, O. H. (1947). On the dual nature of learning: a reinterpretation of 'conditioning' and 'problen-solving'. Harvard Educational Review 17, 102-148.

Owen, S., Boarder, M. R., Feldon, J., Gray, J. A. \& Fillenz, M. (1979). Role of forebrain noradrenaline in reward and nonreward. Proceedings of the 4th International Catecholamine Symposium, California, September 1978 (ed. E. Usdin) (in the press).

Paul, S. M. \& Skolnick, P. (1978). Rapid changes in brain benzodiazepine receptors after experimental seizures. Science 202, 892-894.

Randall, L. O. \& Kappell, B. (1973). Pharmacological activity of some benzodiazepines and their metabolites. In The Benzodiazepines (ed. S. Garattini, E. Mussini and L. O. Randal1), pp. 27-51. Raven Press: New York.

Ransom, B. R. \& Barker, J. L. (1976). Pentobarbital selectively enhances GABA-mediated post-synaptic inhibition in tissue cultured mouse spinal neurons. Brain Research 114, 530-535.

Robertson, H. A., Martin, I. L. \& Candy, J. M. (1978). Differences in benzodiazepine receptor binding in Maudsley reactive and Maudsley non-reactive rats. European Journal of Pharmacology 50, 455-457.

Rolls, E. T. (1975). The Brain and Reward. Pergamon: Oxford.

Schallek, W., Schlosser, W. \& Randall, L. O. (1972). Recent developments in the pharmacology of the benzodiazepines. Advances in Pharmacology and Chemotherapy 10, 119-181.
Soubrié, P., Thiébot, M. H. \& Simon, P. (1978). Enhanced suppressive effects of aversive events induced in rats by picrotoxin: evidence for a GABA control on behavioral inhibition. Abstracts of the 11th Congress of the Collegium Internationale Neurophychopharmacologicum, p. 426.

Squires, C. \& Braestrup, R. F. (1977). Benzodiazepine receptors in rat brain. Nature 266, 732-734.

Stein, L. (1968). Chemistry of reward and punishment. In Psychopharmacology: A Review of Progress 1957-1967 (ed. D. H. Efron), pp. 105-123. US Government Printing Office: Washington, D.C.

Stein, L. \& Wise, D. C. (1972). Possible etiology of schizophrenia: progressive damage to the noradrenergic reward system by endogenous 6-hydroxydopamine. In Neurotransmitters (ed. I. J. Kopin). Research Publications of the Association for Nervous and Mental Disease 50, 298-311.

Stein, L., Wise, C. D. \& Berger, B. D. (1973). Anti-anxiety action of benzodiazepines: decrease in activity of serotonin neurons in the punishment system. In The Benzodiazepines (ed. S. Garattini E. Mussini and L. O. Randall), pp. 299326. Raven Press: New York.

Storm-Mathisen, J. (1978). Localization of putative transmitters in the hippocampal formation (with a note on the connections to septum and hypothalamus). In Functions of the Septo-Hippocampal System (ed. K. Elliott and J. Whelan), pp. 49-79. CIBA Foundation Symposium no. 58 (new series). Elsevier: Amsterdam.

Ungerstedt, U. (1971). Stereotaxic mapping of the monoamine pathways in the rat brain. Acta Physiologica Scandinavica 82, Suppl. 367, 1-48.

Williamson, M.J., Paul, S. M. \& Skolnick, P. (1978). Labelling of benzodiazepine receptors in vivo. Nature 275, $551-553$. 